\title{
In Situ Determination of the Water Content of Ionic Liquids
}

\author{
K. Wippermann, ${ }^{\mathrm{z}}$ J. Giffin, and C. Korte
}

Forschungszentrum Jülich GmbH, Institute of Energy and Climate Research - Fuel Cells (IEK-3), 52425 Jülich, Germany

This study examines the applicability of electrochemical methods to the in situ determination of the water content in proton-conducting ionic liquids (PILs). Two proton-conducting ionic liquids with different acidities and hygroscopicities of the cations, sulfoethylmethylammonium trifluoromethanesulfonate, [2-Sema][TfO] and N,N-diethylmethylammonium trifluoromethanesulfonate, [Dema][TfO], were used. At first, PIL water electrolytes with known water concentrations ([2-Sema][TfO]: 0.64-6.1 wt\%, [Dema][TfO]: 0.18-99.5 $\mathrm{wt} \%)$ were prepared. Then, the influence of the water content on the electrochemical properties, namely the electrical conductivity, charge of hydrogen oxidation, charge of Pt oxide reduction and onset potential of Pt oxidation, were investigated. The four parameters were plotted as a function of the water concentration and fitted by exponential, linear or asymptotic functions. These fits serve as calibration curves that can be used to determine the actual water concentration by measuring one or more of the four parameters investigated. It was found that the measurement of specific ion conductivity is a fast and simple method across a wide range of water concentrations. The evaluation of the Pt oxide reduction charge from cyclic voltammograms is more time-consuming, but provides higher accuracy at low water concentrations, although the accuracy also depends on the nature of the ionic liquid.

(c) The Author(s) 2018. Published by ECS. This is an open access article distributed under the terms of the Creative Commons Attribution Non-Commercial No Derivatives 4.0 License (CC BY-NC-ND, http://creativecommons.org/licenses/by-nc-nd/4.0/), which permits non-commercial reuse, distribution, and reproduction in any medium, provided the original work is not changed in any way and is properly cited. For permission for commercial reuse, please email: oa @ electrochem.org. [DOI: 10.1149/2.0991805jes]

(cc) BY-NC-ND

Manuscript submitted February 2, 2018; revised manuscript received March 23, 2018. Published April 12, 2018.

Ionic liquids (ILs) are known for their promising features, such as a wide electrochemical window, non-inflammability, a negligible vapor pressure and high chemical / thermal stabilities. These properties enable ILs to be used as polar solvents or electrolytes. Depending on the field of application, the presence of liquid or gaseous water in contact with ILs may or may not be desirable. Electrochemical applications, which demand practically anhydrous electrolytes include, for instance, lithium batteries, ${ }^{1,2}$ electrochemical supercapacitors, ${ }^{3,4}$ solar cells, ${ }^{5,6}$ field-effect double-layer transistors ${ }^{7,8}$ and electrochemical synthesis. ${ }^{9,10}$ For other applications, the presence of water is either unavoidable (e.g., fuel cells ${ }^{11-27}$ ) or even desirable (humidity sensors ${ }^{28}$ or drying agents ${ }^{29-32}$ ).

Regardless of whether the presence of water in ionic liquids is intended or not, residual amounts of it must be taken into account for the following reasons: (i) water is a common impurity, which is already present after IL synthesis; and (ii) most of the ionic liquids are strongly hygroscopic, i.e., they uptake water during operation. Some experimental and theoretical studies on the influence of environmental water (vapor) on the hygroscopicity and water sorption of ionic liquids can be found in the literature. ${ }^{33-40}$ This means that even if one succeeded in preparing a virtually water-free IL, it would be difficult to prevent absorption of water under the operating conditions of most applications. In any case, the presence of water changes the IL's physicochemical properties. This includes an increase in the electrical conductivity and a decrease in viscosity, a narrowing of the electrochemical window, hydrolysis, thermal decomposition and a change of reactivity and solvating ability.

While there is plenty of literature available on the bulk properties of binary mixtures of ionic liquids and water (see e.g., Merkel et al. ${ }^{41}$ ), studies of the influence of small or residual water concentrations on the electrochemical behavior of the system metal/IL $+\mathrm{H}_{2} \mathrm{O}$ are fairly scarce. ${ }^{27,42,43}$ Walsh et al. studied the oxygen reduction reaction (ORR) on polycrystalline Pt electrodes in [Dema][TfO]. ${ }^{42}$ They observed an increase of water content of up to $\approx 0.7 \mathrm{wt} \%$ caused by ORR, indicating an ORR process via a 4-electron reduction. In a second publication, Walsh et al. investigated the formation of Pt oxides in ionic liquids via trace water oxidation, taking the hydrazine oxidation reaction as a probe of the reactivity of the Pt oxide layers. ${ }^{43}$ According to the findings of Walsh et al., multiple layers of oxide form at elevated temperatures and potentials. The strong effect of temperature on the thickness of the Pt oxide layers corresponds to the results of our recent

${ }^{\mathrm{z} E-m a i l: ~ k . w i p p e r m a n n @ f z-j u e l i c h . d e ~}$ publication, in which we investigated the electrochemical properties of 2-sulfoethylammonium trifluoromethanesulfonate ([2-SEA][TfO]) and concluded that the adsorption of water is particularly pronounced at elevated temperatures. ${ }^{27}$

Motobayashi et al. ${ }^{44}$ studied water adsorption on $\mathrm{Au}$ electrodes in 1-butyl-3-methyl-imidazolium bis(trifluoromethanesulfonyl)imide ([BMIM][TFSI]) by using combined spectroscopic and electrochemical measurements. They confirmed the simulation results of Feng et al., ${ }^{45}$ especially the strong adsorption of water at high potentials. Zhong et al. $^{46}$ investigated the interface of $\mathrm{Au}(111)$ and 1-butyl-1-methyl-pyrrolidinium bis-(trifluoromethylsulfonyl)-imide ([BMP][TFSI]) by means of AFM. An increase in the bulk water content leads to an increased adsorption of water and a weakening of the interaction between the ions and the gold surface. Recently, Friedl et al. ${ }^{47}$ studied the double layer properties of the interface $\mathrm{Au}$ (111) and [BMP][TFSI] by means of impedance spectroscopy and cyclic voltammograms. They confirmed the increase of water adsorption with increasing potential and the higher affinity of water molecules to the anions. As a main effect of the increasing water adsorption, Friedl et al. found an increase in the double layer capacitance at potentials higher than the potential of zero charge (p.z.c.). The surface charge (zero, positive or negative) strongly affects both the adsorption of ions and water molecules.

As is mentioned in our most recent publication, ${ }^{48}$ extensive measurements of the equilibrium water vapor partial pressure over each PIL as a function of water content and temperature would be necessary to maintain the water concentration at a constant level. This would include a setup with a controlled humidifier and dryer unit. However, these efforts would not ensure a sufficiently fast or even a correct adjustment of the water content: In the case of [2-Sema][TfO], especially at low water content, water removal is very difficult because of the high hygroscopicity. Even though the adjustment is difficult, knowledge of the water content is essential. In the present work, electrochemical in situ methods, namely conductivity measurements and cyclic voltammetry, are used to measure four different parameters (electrical conductivity, the charge of hydrogen oxidation, the charge of Pt oxide reduction and the onset potential of Pt oxidation) on the basis of the water's concentration. Calibration curves are established and the applicability and practicability of the methods is discussed.

Because the applicability of the methods may also depend on the chemical properties of the ionic liquid, the influence of the cation in the proton-conducting ionic liquid on the calculation of the water content was investigated as well. The proton-conducting ionic liquids (PILs) used here are 2-sulfoethylmethylammonium trifluoromethane- 


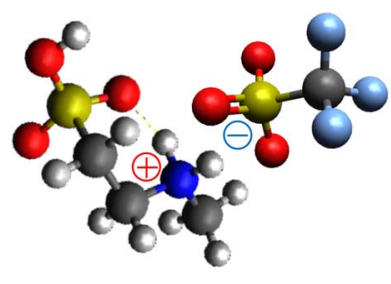

[2-Sema][TfO]

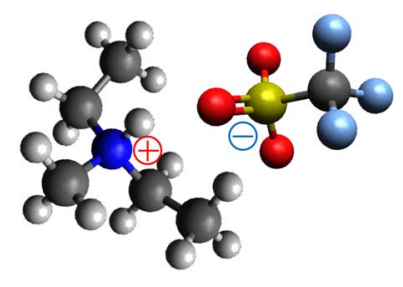

[Dema][TfO]
Figure 1. Molecular structure of the ionic liquids, [2-Sema][TfO] and [Dema][TfO].

sulfonate, [2-Sema][TfO], and N,N-diethylmethylammonium trifluoromethanesulfonate [Dema][TfO]. The molecular structures of both PILs are shown in Fig. 1. They were chosen because the chemical properties of the corresponding bases of the acidic cations, i.e., N-methyltaurine and N,N-diethylmethylamine, differ significantly. Like the homologue, taurine, ${ }^{27} \mathrm{~N}$-methyltaurine or 2 methylaminoethansulfonic acid is a zwitter ion that exists in a tautomeric form and acts both as a proton donor and acceptor:

$$
\begin{aligned}
& \left(\mathrm{CH}_{3}\right) \mathrm{H}_{2} \mathrm{~N}^{+}-\left(\mathrm{CH}_{2}\right)_{2}-\mathrm{SO}_{3} \mathrm{H} \\
& \rightleftarrows\left(\mathrm{CH}_{3}\right) \mathrm{H}_{2} \mathrm{~N}^{+}-\left(\mathrm{CH}_{2}\right)_{2}-\mathrm{SO}_{3}{ }^{-}+\mathrm{H}^{+} \\
& \mathrm{pK}_{\mathrm{s}, 1}=0.94 \pm 0.50^{49} \\
& \left(\mathrm{CH}_{3}\right) \mathrm{H}_{2} \mathrm{~N}^{+}-\left(\mathrm{CH}_{2}\right)_{2}-\mathrm{SO}_{3}^{-} \\
& \rightleftarrows\left(\mathrm{CH}_{3}\right) \mathrm{HN}-\left(\mathrm{CH}_{2}\right)_{2}-\mathrm{SO}_{3}^{-}+\mathrm{H}^{+} \\
& \mathrm{pK}_{\mathrm{s}, 2}=10.16 \pm 0.10^{49}
\end{aligned}
$$

In contrast, $\mathrm{N}, \mathrm{N}$-diethylmethylamine only acts as a proton acceptor:

$$
\begin{aligned}
& \left(\mathrm{CH}_{2}\right)_{2} \mathrm{H}_{2} \mathrm{~N}^{+}-\left(\mathrm{CH}_{2}\right)_{2} \rightleftarrows\left(\mathrm{CH}_{2}\right)_{2} \mathrm{HN}-\left(\mathrm{CH}_{2}\right)_{2}+\mathrm{H}^{+} \\
& \mathrm{pK}_{\mathrm{s}, 1}=10.55 \pm 0.25^{50}
\end{aligned}
$$

In the presence of the super acid trifluoromethanesulfonic acid under anhydrous conditions, both compounds only exist in protonated form. If the $\mathrm{p} K_{\mathrm{a}}$ values of $\left(\mathrm{CH}_{3}\right) \mathrm{H}_{2} \mathrm{~N}^{+}-\left(\mathrm{CH}_{2}\right)_{2}-\mathrm{SO}_{3} \mathrm{H}(0.94)$ and $\left(\mathrm{CH}_{2}\right)_{2} \mathrm{H}_{2} \mathrm{~N}^{+}-\left(\mathrm{CH}_{2}\right)_{2}(10.55)$ are compared, it can be seen that the [2-Sema] cation is strongly acidic, whereas the [Dema] cation only behaves like a very weak acid.

Another difference in the cations is in the number of binding sites that may form hydrogen bonds: In the case of the [2-Sema] cation, five sites $(2 \times \mathrm{N}-\mathrm{H}+2 \times \mathrm{S}=\mathrm{O}+1 \times \mathrm{S}-\mathrm{OH})$ are potentially available, whereas the [Dema] cation has only one N-H site that may form a hydrogen bond. In this study the influence of cation acidity and the ability of forming $\mathrm{H}$ bonds is shown and the effect of the bulk water uptake on the presence of water in the double layer and the structure of the double layer is discussed.

\section{Experimental}

Electrolytes: [2-Sema][TfO], [Dema][TfO] and binary mixtures with water.-[2-Sema][TfO] was prepared by slowly adding trifluoromethanesulfonic acid (reagent grade, 98\%, Sigma Aldrich) to 2methylaminoethansulfonic acid (N-methyltaurine, $\geq 99 \%$, Sigma Life Science). A more detailed description of the preparation process can be found elsewhere. ${ }^{48}$ Coulometric Karl-Fischer titration (852 Titrando / Metrohm company) yielded a water content of $6400 \mathrm{ppm}(0.64 \mathrm{wt} \%)$.

[Dema][TfO] (CAS No.: 945715-39-9), with a nominal purity of $>98 \mathrm{wt} \%$, was purchased from IoLiTec-Ionic Liquids Technologies $\mathrm{GmbH}$. The water content, measured by Karl Fischer titration, is $1800 \mathrm{ppm}(0.18 \mathrm{wt} \%)$. No further purification was performed. The molecular structures of both PILs are shown in Fig. 1.
Binary mixtures of water and the ionic liquids were prepared by adding appropriate amounts of pure water (Milli-Q). In the case of [2Sema][TfO], the water content was varied in a range of 0.64-6.1 wt\%, similarly to water concentrations in high temperature fuel cells (HTPEFC) based on phosphoric acid. ${ }^{51}$ For the example of [Dema][TfO], a larger range of 0.18-99.5 wt\% of water content was used to bridge the gap between low and high water concentrations, i.e., between ionic liquid application conditions and diluted aqueous electrolytes. Because of either evaporation or uptake of water during the electrochemical experiments, the water content of all the electrolytes was determined immediately after recording the last, relevant cyclic voltammogram. This was done by either in situ conductivity measurements ([2-Sema][TfO]) or coulometric Karl Fischer titration ([Dema][TfO]). In the former case, a calibration curve was used that was established by measuring the specific conductivity of [2-Sema][TfO] electrolytes with different water contents (see below).

Electrochemical measurements.-Measuring conditions, cells and electrodes.-The electrochemical measurements were performed at ambient pressure and either a temperature of $25^{\circ} \mathrm{C}$ ([Dema][TfO]), or $90^{\circ} \mathrm{C}$ ([2-Sema][TfO], [Dema][TfO])). $1 \mathrm{~h}$ before and during the complete series of measurements, the gas compartment over the PIL / water electrolytes was purged with dry nitrogen (99.999\%), using a SGT Super Clean Triple Filter by MasCom Technologies GmbH.

The in-house measuring cell and heating unit specially designed for the electrochemical characterization of small volumes (up to $7 \mathrm{ml}$ ) of ionic liquids was described in detail in our recent publications. ${ }^{27,48}$ It consists of a cylindrical Pt crucible $(\emptyset=20 \mathrm{~mm}$, height $=30 \mathrm{~mm})$ as an electrolyte vessel and counter electrode, a $7 \mathrm{~mm}$-long Pt wire working electrode with a diameter of $1 \mathrm{~mm}(99.95 \%$, Goodfellow $\mathrm{GmbH})$ and a self-prepared palladium-hydrogen electrode made of a $1 \mathrm{~mm}$ Pd wire $(99.95 \%$, Goodfellow $\mathrm{GmbH})$. By means of the hydrogen desorption charge obtained from cyclic voltammetry $\left(25^{\circ} \mathrm{C}\right.$ $/ 0.5 \mathrm{M} \mathrm{HClO}_{4}$ ), a roughness factor of 1.23 and an actual Pt electrode surface of $0.28 \mathrm{~cm}^{2}$ was determined.

Measuring devices.-The electrochemical experiments were carried out by means of a "Zennium" electrochemical workstation (ZAHNER Elektrik GmbH). The nitrogen flow rate of $5 \mathrm{ml} / \mathrm{min}$. was adjusted using a Brooks mass flow controller (model "5850S"). The temperature was set by an in-house-designed heating unit described in Wippermann et al. ${ }^{27}$

Cyclic voltammograms $(\mathrm{CVs})$.-- IR-corrected CVs were recorded with a scan rate of $100 \mathrm{mV} / \mathrm{s}$ across a potential range of $0-1.6 \mathrm{~V}$ (RHE). After 10 cycles, stationary voltammograms were obtained. The $10^{\text {th }}$ cycle of each CV was analyzed regarding the charges of hydrogen desorption $/ \mathrm{PtO}_{\mathrm{x}}$ reduction and the $\mathrm{Pt}$ oxidation currents. The double layer charging currents in the potential range of about 0.4 $0.6 \mathrm{~V}$ were taken as baselines for determining the $\mathrm{H}_{\mathrm{UPD}}$ peak charges.

Conductivity measurements.-Firstly, the cell constant as a function of electrolyte volume was determined by impedance measurements with $0.1 \mathrm{M}$ KCL solutions. Then, binary mixtures of [2Sema][TfO] and water were prepared with well-established water concentrations determined by Karl-Fischer titration $\left(\mathrm{c}_{\mathrm{H}_{2} \mathrm{O}}=0.5-5.6\right.$ $\mathrm{wt} \%$ ). Finally, the ohmic resistance of these binary mixtures was measured by means of impedance spectroscopy. The AC amplitude was found to be either $10 \mathrm{mV}\left(\mathrm{T}>50^{\circ} \mathrm{C}\right)$ or $20 \mathrm{mV}\left(\mathrm{T}<50^{\circ} \mathrm{C}\right)$. The temperature was increased in increments of $5^{\circ} \mathrm{C}$ from 30 to $100^{\circ} \mathrm{C}$ and vice versa. The hysteresis of the corresponding heating and cooling cycles was very small, indicating a negligible change of water concentration. By means of the cell constant, calibration curves of the specific ion conductivity vs. water content could be established for the different temperatures. As mentioned above, these calibration curves were used to determine the actual water content of [2-Sema][TfO].

Water uptake experiment.-The water uptake of [Dema][TfO] and [2-Sema][TfO] was examined by exposing both PILs in open glass 


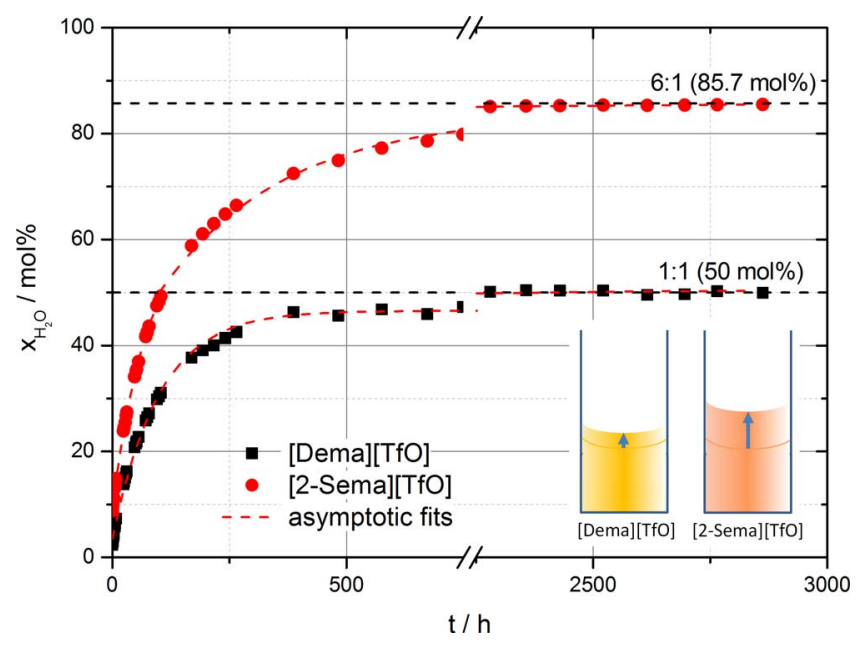

Figure 2. Water uptake experiment with [2-Sema][TfO] and [Dema][TfO], ambient conditions.

vessels to ambient atmosphere $\left(\mathrm{T}=21.5^{\circ} \mathrm{C} \pm 0.4^{\circ} \mathrm{C}, \mathrm{RH}=48.6 \% \pm\right.$ $2.8 \%, \mathrm{p}_{\mathrm{H}_{2} \mathrm{O}}=1241 \mathrm{~Pa} \pm 77 \mathrm{~Pa}$ ) over a period of $2862 \mathrm{~h}$ and measuring the weight at regular intervals. For a better comparison, the same starting volumes $(\approx 6 \mathrm{ml})$ and volume-to-surface ratios $(\approx 1.2 \mathrm{~cm})$ were chosen. It should, however, be noted that the starting values of the water content were different, as described in the Electrolytes' section.

\section{Results and Discussion}

Water uptake of the ionic liquids.-The water uptake of [Dema][TfO] and [2-Sema][TfO] over a period of $2862 \mathrm{~h}$ is compared in Fig. 2. Asymptotic fits reveal the limiting values (see indicated values at red lines) that are close to a molar fraction of $50 \mathrm{~mol} \% \mathrm{H}_{2} \mathrm{O}$ for [Dema][TfO] and $85.7 \mathrm{~mol}^{2} \mathrm{H}_{2} \mathrm{O}$ for [2-Sema][TfO]. These values correspond to molar ratios $\mathrm{H}_{2} \mathrm{O}$ : PIL of 1:1 ([Dema][TfO]) and 6:1 ([Dema][TfO]), which qualitatively reflects the larger number of binding sites for forming hydrogen bridges in the [2-Sema] cation (2 $\mathrm{x} \mathrm{N}-\mathrm{H}+2 \times \mathrm{S}=\mathrm{O}+1 \times \mathrm{S}-\mathrm{OH})$ compared to the [Dema] cation (1 $\mathrm{x}$ $\mathrm{N}-\mathrm{H})$. However, a quantitative correlation is not possible because the detailed (dynamic) structure of the PIL/water mixtures is not known. In any case, [2-Sema][TfO] behaves in a much more hygroscopic manner than [Dema][TfO], with a four times higher water absorption rate $(\approx 27 \mathrm{wt} \%$ vs. $\approx 7 \mathrm{wt} \%)$.

The following parameters may influence the thermodynamics and kinetics of water uptake of ionic liquids as well: (i) hydrophilicity/hydrophobicity (e.g., number of polar groups, length of the alkyl chain, etc.); (ii) extensive parameters like the surface/volume ratio of the ionic liquid or the filling level of IL in the measuring vessel; (iii) operation/ambient conditions like temperature and relative humidity, which affect the difference in water partial pressure over the ionic liquid and in the ambient air. Whereas the conditions described in (ii) and (iii) are identical for [Dema][TfO] and [2-Sema][TfO], those of (i) are obviously different: [2-Sema][TfO] is more hydrophilic (less hydrophobic) than [Dema][TfO], because in comparison to the [Dema] cation, the [2-Sema] cation contains two polar groups $\left(\mathrm{R}-\mathrm{SO}_{3} \mathrm{H}\right.$ and $\mathrm{R}-\mathrm{NH}_{2}{ }^{+}$) instead of one $\left(\mathrm{R}-\mathrm{NH}^{+}\right)$, but only one ethyl group instead of two.

Influence of the water content on a [2-Sema][TfO] electrolyte.Measurements of specific conductivity.-Fig. 3 shows the specific conductivity of [2-Sema][TfO] as a function of the water content in a temperature range of $30-100^{\circ} \mathrm{C}$. The measured values can be well approximated with an exponential fit or, in a semi-logarithmic plot, with a linear function (see inset picture). This can be explained by reference to the following factors:

(i) The specific conductivities and viscosities of neat [2Sema][TfO] are quite similar to those of its homologue, 2-

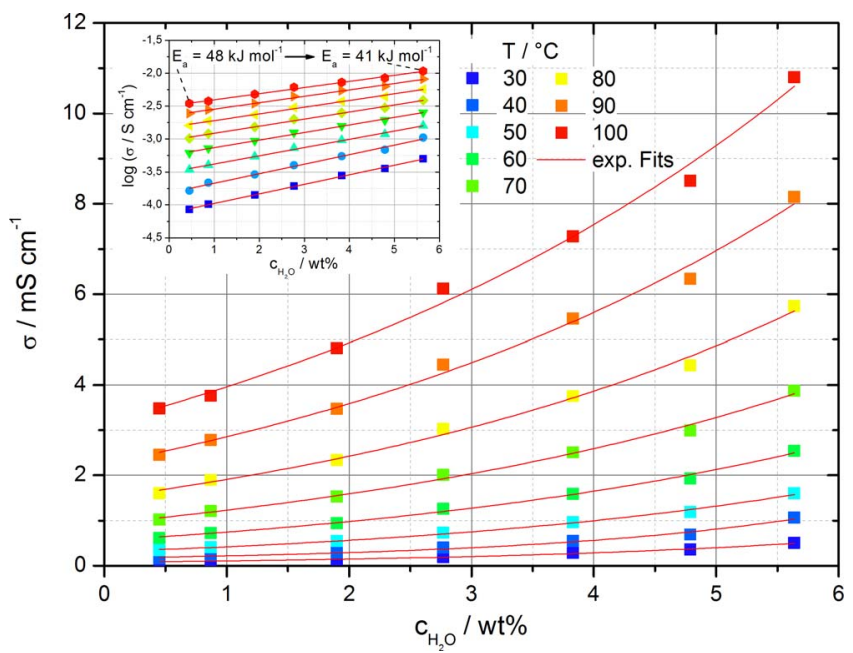

Figure 3. Specific ion conductivity of [2-Sema][TfO]/water electrolytes, $\mathrm{c}_{\mathrm{H}_{2} \mathrm{O}}$ $=0.5-5.6 \mathrm{wt} \%, \mathrm{~T}=30-100^{\circ} \mathrm{C}$; inset picture shows semi-logarithmic plots of the conductivity data.

sulfoethylammonium triflate, [2-Sea][TfO], which have been recently published. ${ }^{48}$ A strong coupling between these parameters can be observed, i.e. in a Walden plot the slope is close to one. In contrast to neat $\mathrm{H}_{3} \mathrm{PO}_{4}$, autoprotolysis should not occur in this type of PILs. A re-protonation of $\left[\mathrm{TfO}^{-}\right.$is unprobable because of a difference of $\sim 10$ orders of magnitude in acidity between triflic acid (comparable to $\mathrm{HClO}_{4}$ ) and the [Sema] ${ }^{+}$cation (comparable to alkane sulfonic acids). Based on these considerations, a pure vehicular mechanism for proton transport in neat $[2-\mathrm{Sema}][\mathrm{TfO}]$ with $[2-\mathrm{Sema}]^{+}$as the only proton carrier is highly probable.

This may be different in the case of increasing water content. Due to the high acidity of the $[\mathrm{Sema}]^{+}$cation, protons will be transferred from [2-Sema] ${ }^{+}$to $\mathrm{H}_{2} \mathrm{O}$ by forming $\mathrm{H}_{3} \mathrm{O}^{+}$. The $\mathrm{H}_{3} \mathrm{O}^{+}$cations are (most likely) much more mobile than the bigger [Sema] ${ }^{+}$cations. Thus, the increasing conductivity with increasing water content can be explained by an increasing concentration of the more mobile protonic charge carrier $\mathrm{H}_{3} \mathrm{O}^{+}$in competition with the slower [Sema $]^{+}$, but still maintaining a vehicular mechanism. On the other hand, due to the comparable acidity of [Sema] ${ }^{+}$and $\mathrm{H}_{3} \mathrm{O}^{+}$a cooperative mechanism between [Sema] ${ }^{+}, \mathrm{H}_{3} \mathrm{O}^{+}$, taurine and $\mathrm{H}_{2} \mathrm{O}$ can be (principially) assumed. The Vogel-Fulcher-Tamman plots (not shown here) reveal a decrease in the activation energy of the ion transport from $48 \mathrm{~kJ}$ $\mathrm{mol}^{-1}\left(0.4 \mathrm{wt} \% \mathrm{H}_{2} \mathrm{O}\right)$ to $41 \mathrm{~kJ} \mathrm{~mol}^{-1}\left(5.6 \mathrm{wt} \% \mathrm{H}_{2} \mathrm{O}\right)$ at $T=100^{\circ} \mathrm{C}$ (see inset picture). The comparable small decrease of $15 \%$ suggests that the vehicular transport by $\mathrm{H}_{3} \mathrm{O}^{+}$may predominate and a cooperative mechanism between [Sema] ${ }^{+}, \mathrm{H}_{3} \mathrm{O}^{+}$, taurine and $\mathrm{H}_{2} \mathrm{O}$ may play only a minor role.

(ii) As was discovered by Nickerson et al., ${ }^{52}$ who performed a combination of experimental and molecular dynamics studies of $[\mathrm{BMIM}][\mathrm{I}]$, in water mixtures, the viscosity decreases exponentially with the amount of water. Because of the strong coupling of viscosity and conductivity, the latter increases exponentially. ${ }^{52}$

For very low water contents of $1 \mathrm{wt} \%$ or less in mixtures of water and imidazolium-based ionic liquids like EMIM-BF4 and EMIM-ES, Vila et al.$^{53}$ provided another physical explanation of the increase of specific conductivity with the water content: the addition of water should decrease the surface tension of the IL/water mixture and increase the diffusion coefficient of the charge carriers. They derived an equation, where the specific conductivity is a function of the inverse square root of the water concentration ${ }^{5.3}$ By using the equation of Vila et al., the specific conductivities plotted in Fig. 3 could be fitted very well for water concentrations less than $2 \mathrm{wt} \%$. As expected, Vila's equation failed to describe the increase of conductivity at water contents higher than $2 \mathrm{wt} \%$. In the range of 0 to $6 \mathrm{wt} \%$ of water, the best fit was obtained with an exponential function. However, it should be 


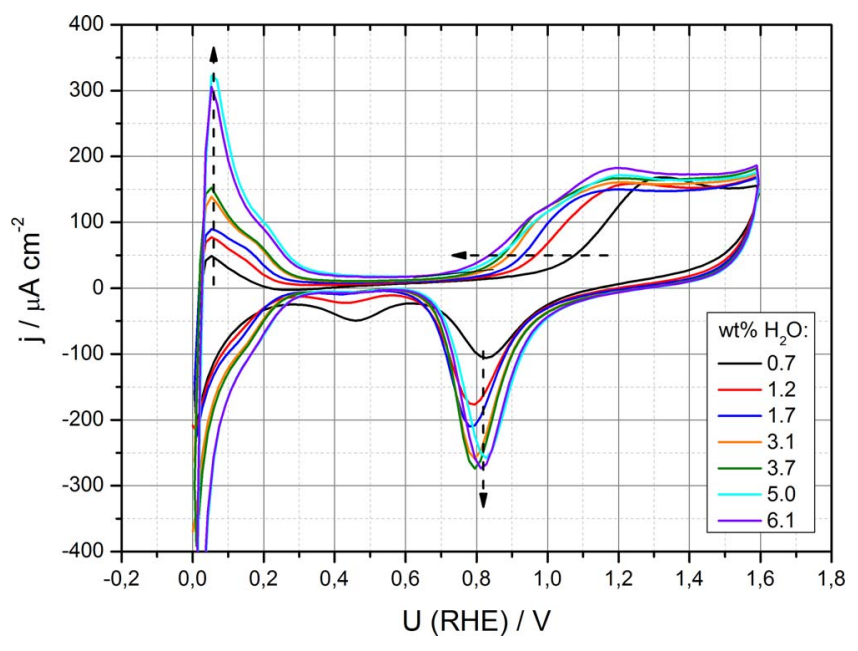

Figure 4. Cyclic voltammograms of $\mathrm{Pt}$ in [2-Sema][TfO]/water electrolytes, always the last cycle of $10 \mathrm{CVs}$ represented, $\mathrm{dU} / \mathrm{dt}=100 \mathrm{mVs}^{-1}, \mathrm{c}_{\mathrm{H}_{2} \mathrm{O}}=0.7$ $-6.1 \mathrm{wt} \%, \mathrm{~T}=90^{\circ} \mathrm{C}$.

kept in mind, that a plot of the specific conductivity of an IL/water mixture in the whole range of the mole fraction of water $(0-1)$ resembles a bell-shaped curve (see e.g. Vila et al. ${ }^{53}$ ), where the exponential function fits the left side of the curve.

If the ionic conductivity of a mixture of [2-Sema][TfO] and water at a certain temperature is known, the actual water concentration of [2-Sema][TfO] can be easily extracted from the linear regression of the semi-logarithmic plots $\log \sigma$ vs. $\mathrm{c}_{\mathrm{H}_{2} \mathrm{O}}$, as shown in the inset picture in Fig. 3.

Cyclic voltammograms.-Fig. 4 shows cyclic voltammograms for mixtures of [2-Sema][TfO]-water with water concentrations up to 6 wt $\%$ at $90^{\circ} \mathrm{C}$. Because a detailed description of the main features of this diagram has already been presented elsewhere, ${ }^{48}$ only a brief survey of the most important features and effects is given in the following: Similar to CVs obtained with diluted acids, roughly three potential regions, including $\mathrm{H}_{\text {upd }}$, double layer and $\mathrm{O}_{\mathrm{x}}$ chemisorption/Pt oxidation, can be distinguished. The second reduction peak, observed at low water concentrations $(0.7 / 1.2 \mathrm{wt} \%)$ at an electrode potential of about $0.45 \mathrm{~V}$, is ascribed to $\mathrm{PtO}_{\mathrm{x}}$ reduction mechanism via [2-Sema] cations, whereas the 'common' reduction process at about $0.8 \mathrm{~V}$ is assumed to proceed without any involvement of $[2-\mathrm{Sema}]^{+}{ }^{48}$ The most important effects caused by an increasing water concentration are indicated by the dashed arrows: (i) an increase of $\mathrm{H}_{\mathrm{upd}}$ charge, $\mathrm{Q}_{\mathrm{H}}$; (ii) a decrease of the onset potential of Pt oxidation, $\mathrm{U}_{@ \mathrm{PtOx}}=50 \mu \mathrm{Acm}^{-2}$; and (iii) an increase of $\mathrm{PtO}_{\mathrm{x}}$ reduction charge, Q Qtox-Red. A detailed analysis of these effects is given below.

$H_{U P D}$ charge.-At first, the total charge obtained from the hydrogen desorption peaks, $\mathrm{Q}_{\mathrm{T}}$, was analyzed. $\mathrm{Q}_{\mathrm{T}}$ is the sum of the hydrogen desorption charge, $\mathrm{Q}_{\mathrm{H}}$, and the anion (cation) ad-/desorption charge, $\mathrm{Q}_{\mathrm{A} / \mathrm{C}}$. In the potential range of $0.4-0.6 \mathrm{~V}$, the double layer charging current, $\mathrm{Q}_{\mathrm{C}}$, can be identified and subtracted as described in the Experimental part. $\mathrm{Q}_{\mathrm{C}}$ tends to increase with the water content, which can be explained by an increase of the dielectric constant and a decrease in the thickness of the double layer. More detailed information can be found in our recent study of the double layer properties of the interface $\mathrm{Pt} /[2-\mathrm{Sema}][\mathrm{TfO}]{ }^{48}$

At potentials close to $0 \mathrm{~V}$ (RHE), not only atomic hydrogen, but also molecular hydrogen is formed. The latter one makes an additional contribution to the total charge. $\mathrm{Q}_{\mathrm{T}}$ was calculated in the $\mathrm{H}_{\mathrm{UPD}}$ potential range ( 0 to $\approx 0.3-0.4 \mathrm{~V}(\mathrm{RHE}))$ and plotted against water content (Fig. 5). A fairly linear plot is obtained, with a slope of 56 $\mu \mathrm{C} \mathrm{cm}-2 / w t \%$ and an intercept of about $19 \mu \mathrm{C} \mathrm{cm}^{-2}$. An obvious reason for the latter result is the charge of ion ad-/desorption as an intrinsic element of $\mathrm{Q}_{\mathrm{T}}$. Another possible explanation becomes appar-

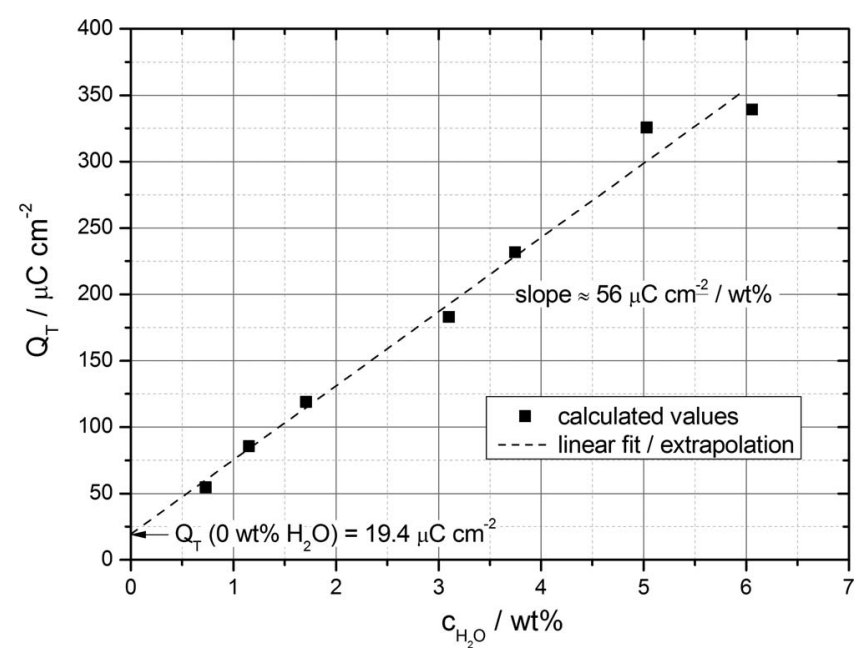

Figure 5. Hydrogen desorption charge densities, calculated from Fig. 4.

ent when considering the possible hydrogen desorption (and adsorption) processes, which could proceed via either $\mathrm{H}_{2} \mathrm{O}$ or unprotonated methyltaurine (B):

$$
\begin{gathered}
\mathrm{Pt}-\mathrm{H}_{\mathrm{ad}}+\mathrm{H}_{2} \mathrm{O} \Leftrightarrow \mathrm{Pt}+\mathrm{H}_{3} \mathrm{O}^{+}+\mathrm{e}^{-} \\
\mathrm{Pt}-\mathrm{H}_{\mathrm{ad}}+\mathrm{B} \Leftrightarrow \mathrm{Pt}+\mathrm{BH}^{+}+\mathrm{e}^{-}
\end{gathered}
$$

At small water contents, reaction ( $3 \mathrm{~b}$ ) should become dominant. If this is the case, reaction ( $3 b$ ) makes an additional contribution to the hydrogen desorption charge even in absence of water. Thus, the $\mathrm{H}_{\text {upd }}$ charge in the water free ionic liquid must be higher than zero, as can be seen in Fig. 5.

The highest $\mathrm{Q}_{\mathrm{T}}$ values measured here exceed the theoretical value of a monolayer of atomic hydrogen on $\mathrm{Pt}\left(210 \mu \mathrm{Ccm}^{-2}\right)$ by about $60 \%$. Clearly, the evolution and oxidation of molecular hydrogen plays a significant role, at least for water concentrations higher than $3 \mathrm{wt} \%$. This is not surprising, as the low potential limit of the cyclic voltammograms is $0 \mathrm{~V}$ instead of $50 \mathrm{mV}$ vs. RHE. $50 \mathrm{mV}$ is the generally accepted value of the low potential limit for diluted aqueous electrolytes when determining the electrochemically-active surface of Pt electrodes. This value represents a compromise between the avoidance of molecular hydrogen formation (lower potential limit not too low) and a determination of $\mathrm{H}_{\text {upd }}$ charge to the fullest extent possible (lower potential limit not too high). However, it should be kept in mind that if the water content becomes small, the $\mathrm{H}_{\text {upd }}$ region shifts to more negative potentials (see Fig. 4) and the lower potential limit must be adapted accordingly. In other words, the lower potential limit of a cyclic voltammogram must be evaluated for each water concentration, which seems to be a rather tedious and impractical procedure. For this reason, it may be more practical to use a constant lower potential limit for the whole range of water concentrations. However, this method must be used with caution for two reasons: (i) at very low water concentrations, the lower potential limit may be too high and only a part of the full $\mathrm{H}_{\mathrm{UPD}}$ charge can be detected; (ii) at higher water concentrations, the evolution and oxidation of molecular hydrogen overlaps the oxidation of the adsorbed hydrogen atoms.

When the $\mathrm{Q}_{\mathrm{T}}$ has been determined, the actual water concentration of [2-Sema][TfO] can be calculated from the linear regression of $\mathrm{Q}_{\mathrm{T}}$ vs. $\mathrm{c}_{\mathrm{H}_{2} \mathrm{O}}$.

Onset potential of Pt oxidation / charge of PtO $\mathrm{O}_{x}$ reduction.-In contrast to the hydrogen adsorption / desorption processes, Pt oxidation and thus $\mathrm{PtO}_{\mathrm{x}}$ reduction cannot take place without the presence of water. In the case of a current density of $50 \mu \mathrm{A} \mathrm{cm}^{-2}$, the onset potential of $\mathrm{Pt}$ oxidation vs. water concentration is shown in Fig. 6 (left axis). The exponential decrease of $\mathrm{U}_{@ \mathrm{PtOx}}=50 \mu \mathrm{Acm}^{-2}$ with the increasing bulk water content suggests a strong increase in the water 


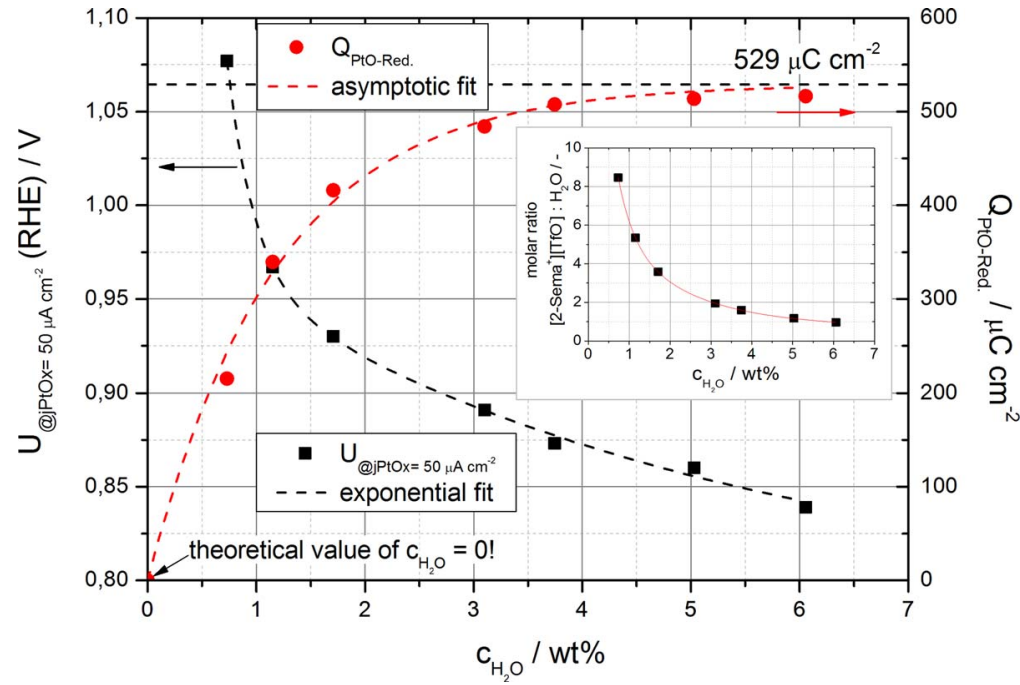

Figure 6. Onset potential of Pt oxidation at $50 \mu \mathrm{A} \mathrm{cm}^{-2}$ and $\mathrm{PtO}_{\mathrm{x}}$ reduction charge, calculated from Fig. 4; inset picture shows molar ratio $[2-\mathrm{Sema}][\mathrm{TfO}] /$ water. coverage on the Pt surface at water concentrations of less than $2 \mathrm{wt} \%$ and a smaller increase in the presence of higher water contents. Because the water coverage correlates with the bulk water concentration, the decay of $\mathrm{U}_{@ \mathrm{PtOx}}=50 \mu \mathrm{Acm}^{-2}$ follows approximately the curve of the molar ratio of [2-Sema][TfO]: $\mathrm{H}_{2} \mathrm{O}$ in the bulk electrolyte (see inset picture in Fig. 6).

Because the formation of Pt oxide is closely linked to the coverage of water molecules on the Pt surface and the relative increase of the molar water concentration gets smaller with increasing water content, it is not surprising that, compared to the $\mathrm{PtO}_{\mathrm{x}}$ onset potential, the $\mathrm{PtO}_{\mathrm{x}}$ reduction charge has an inverse relationship with the water content (right axis in Fig. 6). The Pt oxidation current in the passive region is virtually independent of the water concentration (in the range investigated) and the upper potential is identical for all CVs. Hence, the overall charge of $\mathrm{Pt}$ oxidation/reduction must inversely correlate with the onset potential of $\mathrm{Pt}$ oxidation. The asymptotic behavior suggests the formation of a $\mathrm{PtO}_{\mathrm{x}}$ film with more or less constant thickness, even at low water concentrations of about 5-6 wt \%. This means that with regard to Pt oxidation, [2-Sema][TfO] with a water content of only $6 \mathrm{wt} \%$ behaves similarly to aqueous acidic solutions, where comparable onset potentials of Pt oxidation and Pt oxidation currents are obtained. Moreover, the similar behavior suggests that [2-Sema][TfO] (partly) desorbs and a thin $\mathrm{PtO}_{\mathrm{x}}$ layer is formed, corresponding to the mechanism known from aqueous solutions. The asymptotic value of about $530 \mu \mathrm{C} \mathrm{cm}^{-2}$ can be interpreted as a monolayer of Pt oxide, where a theoretical charge of $440 \mu \mathrm{C} \mathrm{cm}^{-2}$ would be expected if only $\mathrm{PtO}$ would form. ${ }^{43}$ At very low water contents $(<2 \mathrm{wt} \%)$, the $\mathrm{PtO}_{\mathrm{x}}$ reduction charge drops steeply down to a theoretical value of zero if the ionic liquid is anhydrous. As can be seen in Fig. 6, the changes in both the $\mathrm{PtO}_{\mathrm{x}}$ onset potential and $\mathrm{PtO}_{\mathrm{x}}$ reduction charge are particularly high in the presence of low or even residual amounts of water. Hence, these methods are especially sensitive for determining small water concentrations.

Influence of the water content on a [Dema][TfO] electrolyte.-In the case of [Dema][TfO], the influence of water concentration in PILwater mixtures was varied across a wide range of concentrations, from $0.18-99.5 \mathrm{wt} \%$, representing the full range from a virtually water-free ionic liquid $(0.18 \mathrm{wt} \%)$, PIL-water mixtures under HTPEFC operating conditions (up to $\approx 9 \mathrm{wt} \%$ ) and concentrated aqueous solutions to diluted aqueous solutions. Moreover, cyclic voltammograms were recorded at different temperatures of $25^{\circ} \mathrm{C}$ and $90^{\circ} \mathrm{C}$ (see Fig. 7a/7b).

Cyclic voltammograms.-The basic features of the cyclic voltammograms shown in Fig. 7 are similar to those presented in Fig. 4 for [2-Sema][TfO]. However, there is an important difference: in order to achieve similar effects, much higher bulk water concentrations are required in the case of [Dema][TfO] compared to [2-Sema][TfO]. For example, a peak current density of $\mathrm{PtO}_{\mathrm{x}}$ reduction of about $-300 \mu \mathrm{A}$ $\mathrm{cm}^{-2}$ is obtained with $\approx 6 \mathrm{wt} \%$ of water in case of a [2-Sema][TfO]water mixture (Fig. 4 ), but requires $\approx 42 \mathrm{wt} \%$ of water in a mixture with [Dema][TfO] (Fig. 7b). In the same way, the second reduction
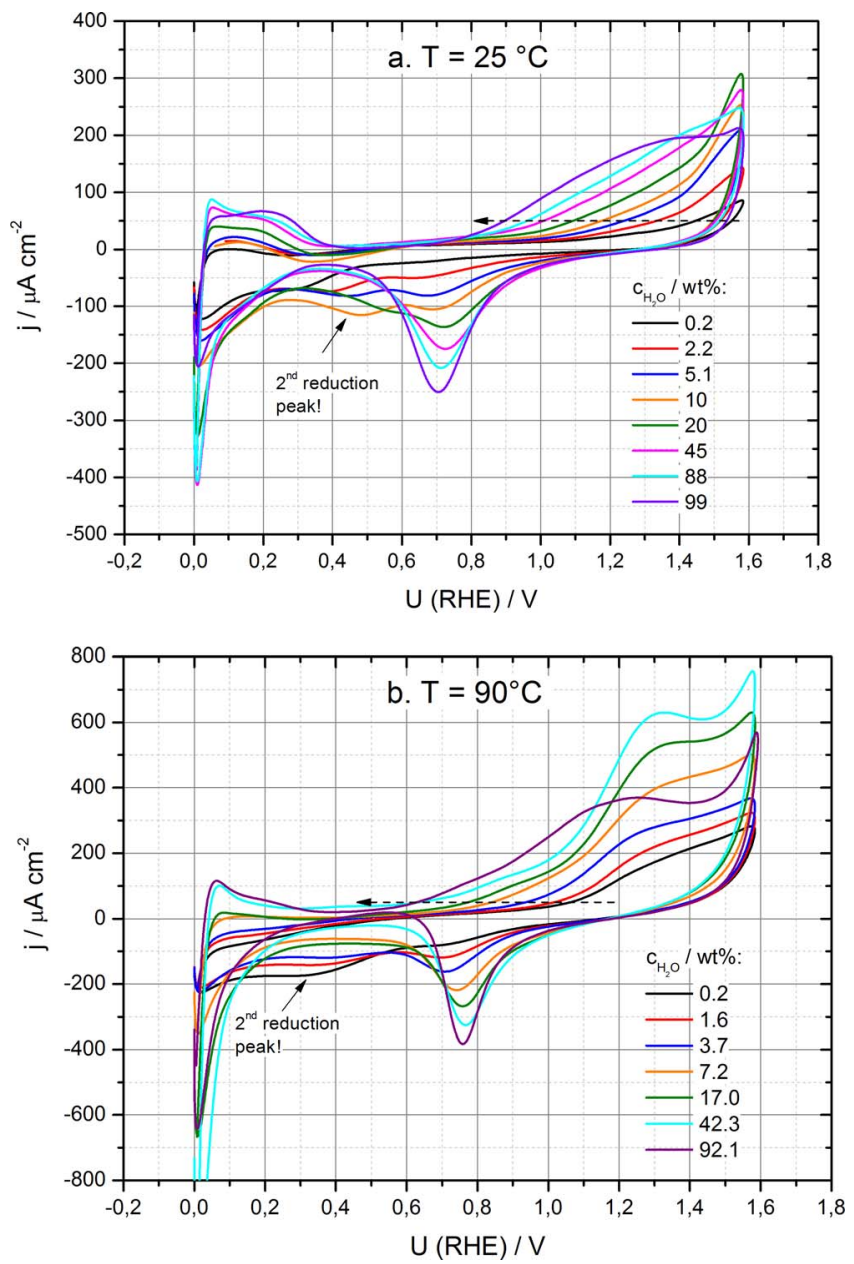

Figure 7. Cyclic voltammograms of $\mathrm{Pt}$ in [Dema][TfO]/water electrolytes, always the last cycle of $10 \mathrm{CVs}$ represented; for the sake of clarity, only selected CVs are shown; $\mathrm{dU} / \mathrm{dt}=100 \mathrm{mVs}^{-1} ; \mathrm{a} . \mathrm{T}=25^{\circ} \mathrm{C}, \mathrm{c}_{\mathrm{H}_{2} \mathrm{O}}=0.2-99.0$ $\mathrm{wt} \%$; b. T $=90^{\circ} \mathrm{C}, \mathrm{c}_{\mathrm{H}_{2} \mathrm{O}}=0.2-92.1 \mathrm{wt} \%$. 


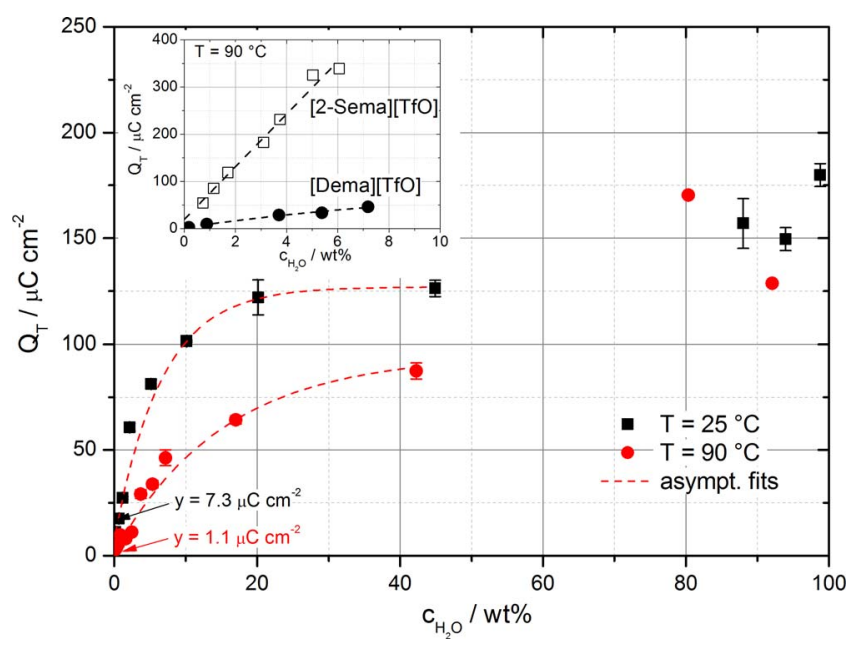

Figure 8. Hydrogen desorption charge densities, calculated from CVs partly shown in Fig. 7; inset picture shows a comparison of $\mathrm{H}_{U P D}$ charges for [2Sema][TfO] and [Dema][TfO] at $90^{\circ} \mathrm{C}$.

peak of around $0.4 \mathrm{~V}$ vanishes at water contents higher than $1.2 \mathrm{wt} \%$ in the case of [2-Sema][TfO] (Fig. 4), compared to a much higher water concentration of more than $17 \mathrm{wt} \%$ for [Dema][TfO] (Fig. 7b). In light of the foregoing discussion, these results suggest a much higher water content / coverage in the double layer of the Pt/[2-Sema][TfO] interface compared to that of the $\mathrm{Pt} /[\mathrm{Dema}][\mathrm{TfO}]$ interface. It is therefore reasonable to assume that for small water concentrations relevant for HTPEFC operation, the double layer with [Dema][TfO] is more similar to the ordered structure of a water-free ionic liquid, whereas the double layer with [2-Sema][TfO] more resembles a hydrogen-bonded network of ions and water (see also former publication ${ }^{48}$ ).

A comparison of Fig. 7a/b shows that the increase of temperature from $25^{\circ} \mathrm{C}$ to $90^{\circ} \mathrm{C}$ causes a doubling of the current densities. At the same time, the ratio of the $\mathrm{Pt}$ oxidation and $\mathrm{PtO}_{\mathrm{x}}$ reduction charges increases. This result suggests a strong thermal activation of faradaic processes that do not contribute to $\mathrm{Pt}$ oxide formation, such as $\mathrm{Pt}$ corrosion, oxygen evolution and oxidation of impurities present in the ionic liquid (purity of [Dema][TfO] $\geq 98 \mathrm{wt} \%$, see experimental part). At elevated temperatures and high water concentrations, the $\mathrm{Pt}$ oxidation current decreases. This effect could be explained by the dilution of impurities and/or a reduced corrosion rate of Pt because of a lower acid concentration, similar to the results reported by Furuya et al. ${ }^{54}$

$H_{U P D}$ charge.-Fig. 8 shows plots of the total charge $\mathrm{Q}_{\mathrm{T}}$ obtained from the hydrogen desorption peaks vs. water concentration for temperatures of $25^{\circ} \mathrm{C}$ and $90^{\circ} \mathrm{C}$. The error bars indicate the mean standard deviation of five calculations of $\mathrm{Q}_{\mathrm{T}}$ for each water concentration. For small water concentrations, the increase of $\mathrm{Q}_{\mathrm{T}}$ can be roughly approximated by a linear function, similar to the result shown in Fig. 5. However, at medium water contents of up to $40-50 \mathrm{wt} \%$, both curves show asymptotic behavior, with limiting values clearly below the charge of $210 \mu \mathrm{C} \mathrm{cm} \mathrm{cm}^{-2}$ which corresponds to a monolayer of hydrogen. This means that in contrast to [2-Sema][TfO], the formation and oxidation of molecular hydrogen seems to be less important. Otherwise, much higher charge densities would be obtained (compare, e.g., Fig. 5). However, at water concentrations higher than 50 $\mathrm{wt} \%, \mathrm{Q}_{\mathrm{T}}$ increases further and the ratio of the charges of adsorption and desorption of hydrogen increase. Both results suggest a growing influence of the oxidation of molecular hydrogen. This can be easily explained by a lower coverage of ions in diluted aqueous solutions and thus a less inhibiting effect of the $\mathrm{H}_{\mathrm{UPD}}$ processes.

The inset picture shows a comparison of the $\mathrm{Q}_{\mathrm{T}}$ values at $90^{\circ} \mathrm{C}$ and low water concentrations for [2-Sema][TfO] (data taken from Fig. 5) and [Dema][TfO]. It is evident that for a given water concentration the $\mathrm{H}_{\mathrm{UPD}}$ charge in presence of [2-Sema][TfO] is significantly higher, which means a faster $\mathrm{H}_{\text {UPD }}$ process in presence of the strongly acidic [2-Sema] cations $(\mathrm{pKa}=0.94)$ compared to the weakly acidic [Dema] cations $(\mathrm{pKa}=10.55)$. The considerable increase of the $\mathrm{H}_{\mathrm{UPD}}$ charge with increasing water content for both proton conducting ionic liquids suggests that water plays a key role in the $\mathrm{H}_{\mathrm{UPD}}$ reaction, which, conversely, means that the cations of both ionic liquids do not (directly) supply $\mathrm{H}^{+}$for the $\mathrm{H}_{U P D}$ reaction. Thus, reaction (3b) is less important or even negligible. It should be kept in mind, that the residual charge $\mathrm{Q}_{\mathrm{T}}$ in water-free ionic liquids could be explained solely by ion adsorption. Because the [Dema] cation is a much weaker proton donor than the [2-Sema] cation, the concentration of $\mathrm{H}_{3} \mathrm{O}^{+}$in $[$ Dema][TfO]/water mixtures should be much lower than that in [2$\mathrm{Sema}][\mathrm{TfO}] /$ water mixtures. If we assume, that reaction (3a) proceeds much faster than reaction (3b), this would explain the higher $\mathrm{H}_{\mathrm{UPD}}$ charge in [2-Sema][TfO]/water mixtures. Moreover, the stronger hygroscopicity of [2-Sema][TfO] compared to [Dema][TfO], including a larger number of binding sites for forming hydrogen bridges, may increase the water content of the double layer and thus support reaction (3a). However, a detailed investigation of the double layer structure including the water content has not been done so far and is beyond the scope of this work.

The asymptotic $\mathrm{Q}_{\mathrm{T}}$ value at water concentrations higher than 50 wt $\%$ and a temperature of $25^{\circ} \mathrm{C}\left(127 \mu \mathrm{C} \mathrm{cm}^{-2}\right)$ is about one third higher than the value at $90^{\circ} \mathrm{C}\left(95 \mu \mathrm{C} \mathrm{cm}^{-2}\right)$. This tendency corresponds to measurements carried out with diluted acid electrolytes. ${ }^{55,56}$ However, in the latter case the effect was found to be higher. For example, Zolfaghari et al. found a similar decrease of $\mathrm{Q}_{\mathrm{T}}$ of about $30 \%$ on $\mathrm{Pt}(100)$ in $0.5 \mathrm{M} \mathrm{H}_{2} \mathrm{SO}_{4}$, but in a much smaller temperature range of 20 to $55^{\circ} \mathrm{C}^{55}$ They attributed their result to a temperature-dependent decrease of $\mathrm{H}_{\mathrm{UPD}}$ and anion surface coverages due to lateral repulsive interactions. In our case, the adsorption of both anions and cations must be considered. The co-sorption of anions and cations would probably decrease the lateral repulsive forces and reduce the effect of temperature, as observed here.

A precise determination of small water concentrations in [Dema][TfO] on the basis of the $\mathrm{H}_{\mathrm{UPD}}$ charge, especially at elevated temperatures, appears to be difficult to achieve for the following reasons: (i) weakly-pronounced hydrogen adsorption/desorption peaks leading to large relative errors of $\mathrm{Q}_{\mathrm{T}}$; (ii) a complex overlap of hydrogen, anion and cation adsorption; (iii) an additional charge because of the formation and oxidation of molecular hydrogen.

Onset potential of Pt oxidation.-Fig. 9 shows the onset potential of Pt oxidation for [Dema][TfO]-water mixtures for temperatures of $25^{\circ} \mathrm{C}$ and $90^{\circ} \mathrm{C}$. The exponential decay at low water concentrations can be explained in the same way as that observed for [2-Sema][TfO]water mixtures (see Fig. 6). The inset picture demonstrates that a variation of the current density chosen for the determination of the onset potential obviously changes the calibration (exponential fit) curves quantitatively, but the shape remains the same. At high water concentrations of $>90 \mathrm{wt} \%$, the onset potential decreases more quickly, leading to s-shaped curves over the entire concentration range of the water. The quick decrease in the onset potential can be interpreted by a decrease in ion coverage and corresponding increase in water coverage on the Pt surface. This interpretation is supported by results obtained by Zolfaghari et al. ${ }^{57}$ For aqueous sulfuric acid, they found a saturation coverage for the adsorption of $\mathrm{HSO}_{4}{ }^{-}$und $\mathrm{SO}_{4}{ }^{2-}$ ions between 0.001-0.01 $\mathrm{M} \mathrm{H}_{2} \mathrm{SO}_{4}$. For [Dema][TfO]-water electrolytes, these values correspond to water concentrations of about 99.5-95 $\mathrm{wt} \%$. This means that, starting from the highest water concentration, the coverage of [Dema] and [TfO] ions follows the increasing bulk ion concentration when the water concentration decreases. At water contents lower than $90 \mathrm{wt} \%$, the saturation coverage of both the ions and water molecules is achieved and the onset potential increases only slightly in a broad range of water concentration in which water is present. If the water content falls below $20 \mathrm{wt} \%$ (77 $\mathrm{mol} \%$ ), the ion and water concentrations have the same order of magnitude and the water coverage depends on the bulk water concentration, i.e., it 


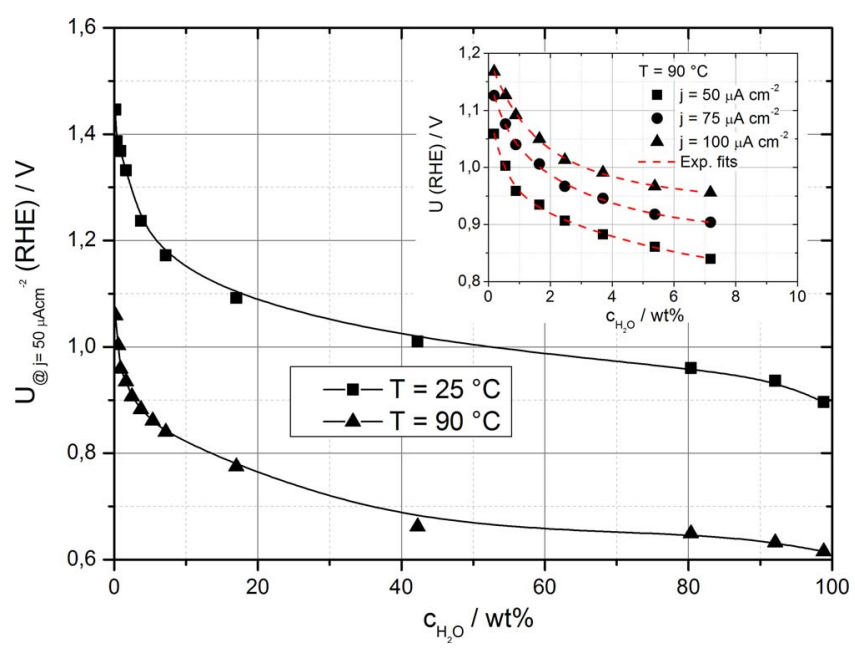

Figure 9. Onset potential of Pt oxidation at $50 \mu \mathrm{A} \mathrm{cm}{ }^{-2}$, calculated from CVs partly shown in Fig. 7; inset picture shows onset potentials at different current densities and low water concentrations $\left(\mathrm{T}=90^{\circ} \mathrm{C}\right)$.

exponentially decreases. Correspondingly, the onset potential starts to increase exponentially. The lower onset potential of Pt oxidation for $90^{\circ} \mathrm{C}$ compared to the values at $25^{\circ} \mathrm{C}$ indicates that the Pt oxidation/reduction process becomes more reversible as the temperature is increased.

On the whole, it can be stated that the method of onset potential of Pt oxidation seems to be especially sensitive in the range of low water contents, where the onset potential changes significantly, i.e., $\mathrm{c}_{\mathrm{H}_{2} \mathrm{O}}$ $<2 \mathrm{wt} \%$ for [2SEMA][TfO] and $\mathrm{c}_{\mathrm{H}_{2} \mathrm{O}}<10 \mathrm{wt} \%$ for [Dema][TfO]. For the example of [Dema][TfO]-water mixtures, it was shown that in a broad range of water concentration $(\approx 10-90 \mathrm{wt} \%)$, the onset potential changes only slightly. Here, the method seems to be less sensitive and thus more inaccurate.

Charge of $\mathrm{PtO}_{x}$ reduction.-The charge of $\mathrm{PtO}_{\mathrm{x}}$ reduction in [Dema][TfO]-water electrolytes is shown in Fig. 10. Unlike the linear plot in Fig. 6, the water concentration is shown on a logarithmic scale. This representation makes it easier to recognize the two steps that are obtained at an elevated temperature of $90^{\circ} \mathrm{C}$, whereas at $25^{\circ} \mathrm{C}$, only one step is observed. The interpretation of the first step and corresponding limiting charge calculated by asymptotic fits is similar to

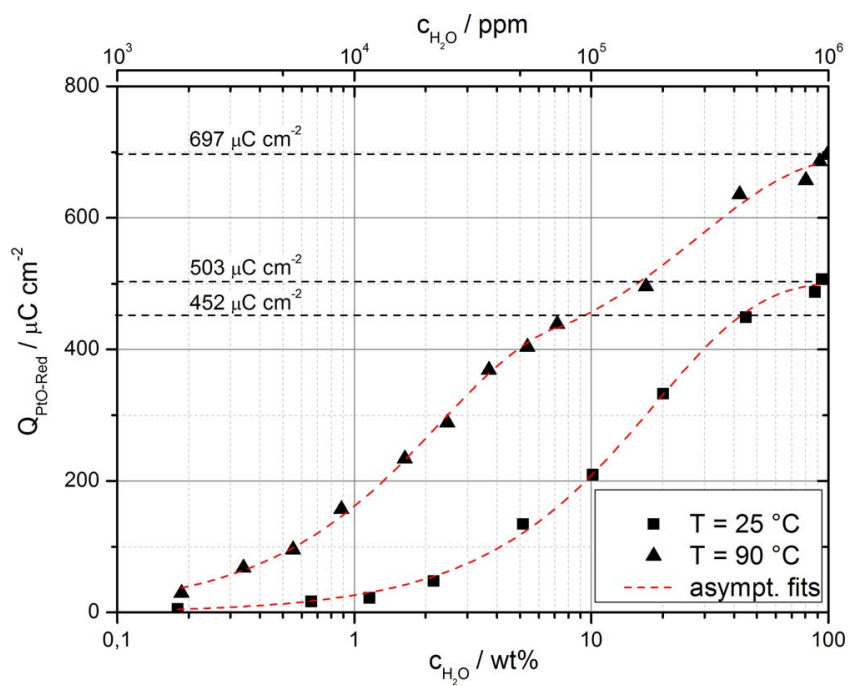

Figure 10. $\mathrm{PtO}_{\mathrm{x}}$ reduction charge, calculated from CVs partly shown in Fig. 7. that described for the Pt oxide layers formed in the presence of [2Sema][TfO]: a monolayer of Pt oxide is generated, corresponding to a limiting charge of about $500 \mu \mathrm{C} \mathrm{cm}^{-2}$. These values are reached at $\approx 10 \mathrm{wt} \%\left(90^{\circ} \mathrm{C}\right)$ and $\approx 100 \mathrm{wt} \%\left(25^{\circ} \mathrm{C}\right)$ of water concentration, i.e., two and twenty times higher than the value of about $5 \mathrm{wt} \%$ in case of [2-Sema][TfO]. This result fits very well to the observation that higher bulk water concentrations are required in the case of [Dema][TfO] to obtain similar effects.

For [Dema][TfO]-water electrolytes at $90^{\circ} \mathrm{C}$ and high water concentrations, a second step occurs that corresponds to a limiting reduction charge of approximately $700 \mu \mathrm{C} \mathrm{cm}^{-2}$. This result suggests further growth of the oxide film, exceeding one monolayer. Walsh et al. $^{43}$ studied the system Pt / [Dema][TfO] and found multiple layers of oxides at elevated temperatures. Unlike our own measurements, these multilayers were observed even at trace water contents of $240 \mathrm{ppm}$; however, at a much higher potential limit of $2 \mathrm{~V}$ (in this work: $1.6 \mathrm{~V})$. Obviously, additional activation energy is required to form 3D layers of Pt oxide. At the same time, a sufficient concentration of bulk water must be available near the Pt surface to generate sufficiently high coverages of water.

Another aspect is the influence of the cations and the anions on the $\mathrm{PtO}_{\mathrm{x}}$ formation and reduction. With increasing bulk ion concentration, the ion coverage should increase, while the coverage of water molecules should decrease, leading to the lower coverage of oxide species and to a thinner $\mathrm{PtO}_{\mathrm{x}}$ film, respectively. However, according to Furuya et al., ${ }^{54}$ anions like $\mathrm{CF}_{3} \mathrm{SO}_{3}{ }^{-}, \mathrm{HSO}_{4}{ }^{-}$and $\mathrm{SO}_{4}{ }^{2-}$ more or less completely desorb when $\mathrm{PtO}_{\mathrm{x}}$ is formed. Nevertheless, even the desorbed ions have an indirect influence on oxide formation, in particular on place-exchange processes, because they change the electrical field in the double layer and/or oxide film ('long-range electrostatic interactions' $).{ }^{58}$ Such an effect could also be caused by [Dema] cations and [TfO] anions. The question of how exactly these ions would affect the electrical field cannot be answered on the basis of what has been discussed so far and should be subject to further investigation.

The high sensitivity of the $\mathrm{PtO}_{\mathrm{x}}$ reduction charge with regard to small changes in the low water contents may be used to precisely determine small concentrations of residual water or even trace water. It is reasonable to assume that this applies not only to [2-Sema][TfO] and [Dema][TfO] in particular, but also to ionic liquids in general. Alongside the high sensitivity at low water concentrations, the analysis of the $\mathrm{PtO}_{\mathrm{x}}$ reduction charge offers some further advantages compared to the other methods: (i) because water molecules are mandatory for Pt oxidation, the fit curves always start at the origin, which improves the accuracy of the fitting procedure; (ii) in contrast to the calculation of the $\mathrm{H}_{\mathrm{UPD}}$ charge at constant lower potential limit, the full $\mathrm{PtO}_{\mathrm{x}}$ reduction charge is always determined from cyclic voltammograms; (iii) provided that the ionic liquid is chemically-stable and there is no significant oxygen evolution, there is no overlap of disturbing charges originating from faradaic reactions.

\section{Conclusions}

The vast majority of proton-conducting ionic liquids (PILs) are strongly hygroscopic electrolytes which, depending on the difference of water vapor partial pressure over the ionic liquid and ambient air, absorb or release water during electrochemical experiments. Because the water content has a significant influence on the physico-chemical properties of PILs, knowledge of the actual water concentration is essential. For practical reasons, simple, common in situ methods such as conductivity measurements and cyclic voltammetry are preferred.

The goal of this work was to prove the applicability of these techniques. The accuracy of the methods is discussed on a qualitative level. Quantitative data regarding the precision of the methods would require further studies, including a larger number of ionic liquids. However, in order to cover a wider range of physico-chemical properties, we used two PILs with very different acidities and hygroscopicities: the [2-Sema] cation of [2-Sema][TfO], a novel PIL recently published, ${ }^{48}$ is much more acidic and hygroscopic compared to the [Dema] cation 
of [Dema][TfO], a PIL that is well-known from the literature (see e.g. Lee et al. ${ }^{20}$ ).

The measurement of specific ion conductivity, $\sigma$, is the quickest and easiest method for determining the water concentration in situ. In the best case, a single frequency impedance measurement for only a few seconds is sufficient to determine the specific ion conductivity and thus the actual water concentration. Moreover, the semi-logarithmic plot of $\sigma$ vs. water concentration can be well-approximated by a linear calibration curve. However, because of the exponential increase of $\sigma$ with the water concentration, the smallest change in specific ion conductivity and thus the lowest accuracy will be obtained at very small water concentrations.

By contrast, the recording and analysis of cyclic voltammograms is more time-consuming, but the evaluated parameters are especially sensitive to low water concentrations. The plots of the charge of hydrogen oxidation, the charge of Pt oxide reduction and the onset potential of Pt oxidation can be well approximated by asymptotic and/or exponential functions. The most accurate results should be obtained by the evaluation of the $\mathrm{PtO}_{\mathrm{x}}$ reduction peak. Unlike the charge of hydrogen oxidation and the onset potential of Pt oxidation, the fit curves always start at the origin. Further advantages over the charge of hydrogen oxidation include: (i) determination of the full $\mathrm{PtO}_{\mathrm{x}}$ reduction charge; and (ii) no overlap of disturbing charges due to faradaic processes.

The accuracy of the determination of the water concentration also depends on the nature of the ionic liquid. This becomes particularly evident at water contents lower than $1 \mathrm{wt} \%$ : for [2-Sema][TfO], pronounced $\mathrm{PtO}_{\mathrm{x}}$ reduction peaks are observed, whereas in the case of [Dema][TfO], the reduction peaks appear less significant. Moreover, the biggest change of the $\mathrm{PtO}_{\mathrm{x}}$ reduction charge occurs below $10 \mathrm{wt} \%$ in the case of [Dema][TfO], but below $2 \mathrm{wt} \%$ for [2-Sema][TfO]. Both effects result in a higher accuracy of determination of small water concentrations for [2-Sema][TfO]. The results suggest that in the presence of strongly hygroscopic PILs like [2-Sema][TfO], which have the potential to form extensive hydrogen-bonded networks, water coverage on the Pt surface seems to be higher and the oxidation of Pt less inhibited. In any case, the results obtained so far indicate different double layer structures in the presence of [2-Sema][TfO] and [Dema][TfO], a topic that requires further study.

In conclusion, it can be stated that the measurement of specific ion conductivity is the most favorable in situ method over a wide range of water concentrations, but is not very accurate with small amounts of water. In the latter case, the evaluation of cyclic voltammograms, especially the analysis of the $\mathrm{PtO}_{\mathrm{x}}$ reduction peak, is the method of choice. However, the significance of the reduction peaks at small water concentrations also depends on the nature of the ionic liquid. A combination of the methods presented in this work would further improve the accuracy of the in situ determination of water concentrations in ionic liquids.

\section{Acknowledgments}

We gratefully acknowledge the preparation and Karl-Fischer titration of the electrolytes by K. Klafki and J. Stremme. We are obliged to $\mathrm{C}$. Wood for proofreading the manuscript.

\section{ORCID}

\section{K. Wippermann (D) https://orcid.org/0000-0002-5489-9280}

\section{References}

1. G. B. Appetecchi, G. T. Kim, M. Montanino, M. Carewska, R. Marcilla, D. Mecerreyes, and I. De Meatza, J. Power Sources, 195, 3668 (2010).

2. M. Li, B. Yang, W. Zhu, P. Zhang, Y. Chao, S. Dai, H. Li, Q. He, and A. Borisevich, Small, 12, 3535 (2016).

3. S. Kondrat, N. Georgi, M. V. Fedorov, and A. A. Kornyshev, Phys. Chem. Chem. Phys., 13, 11359 (2011)

4. C. Largeot, C. Portet, J. Chmiola, P.-L. Taberna, Y. Gogotsi, and P. Simon, J. Am. Chem. Soc., 130, 2730 (2008).
5. J. Chen, D. L. Officer, J. M. Pringle, D. R. MacFarlane, C. O. Too, and G. G. Wallace, Electrochem. Solid-State Lett., 8, A528 (2005).

6. T. Stergiopoulos, M. Konstantakou, and P. Falaras, RSC Adv., 3, 15014 (2013).

7. S. Ono, K. Miwa, S. Seki, and J. Takeya, Org. Electron., 10, 1579 (2009).

8. H. Yuan, H. Shimotani, A. Tsukazaki, A. Ohtomo, M. Kawasaki, and Y. Iwasa, $A d v$. Funct. Mater, 19, 1046 (2009).

9. T. Fuchigami and H. Ishii, Electrochemistry (Tokyo, Jpn.), 70, 46 (2002).

10. M. Feroci, M. Orsini, L. Rossi, and A. Inesi, Curr. Org. Synth., 9, 40 (2012)

11. S.-Y. Lee, T. Yasuda, and M. Watanabe, J. Power Sources, 195, $5909(2010)$

12. A. Noda, M. A. B. H. Susan, K. Kudo, S. Mitsushima, K. Hayamizu, and M. Watanabe, J. Phys. Chem. B, 107, 4024 (2003).

13. S.-Y. Lee, A. Ogawa, M. Kanno, H. Nakamoto, T. Yasuda, and M. Watanabe, J. Am. Chem. Soc., 132, 2183 (2010).

14. T. Yasuda and M. Watanabe, MRS Bull., 38, 560 (2013).

15. K. D. Kreuer, A. Rabenau, and W. Weppner, Angew. Chem., 94, 224 (1982).

16. J.-P. Belieres, D. Gervasio, and C. A. Angell, Chemical Communications, 4799 (2006).

17. R. Hagiwara, T. Nohira, K. Matsumoto, and Y. Tamba, Electrochem. Solid-State Lett., 8, A231 (2005).

18. P. Kiatkittikul, T. Nohira, and R. Hagiwara, J. Power Sources, 220, 10 (2012).

19. S. Y. Kim, S. Kim, and M. J. Park, Nat. Commun., 1, Kim1/1 (2010).

20. S.-Y. Lee, A. Ogawa, M. Kanno, H. Nakamoto, T. Yasuda, and M. Watanabe, J Am Chem Soc, 132, 9764 (2010).

21. M. Mamlouk, P. Ocon, and K. Scott, J. Power Sources, 245, 915 (2014)

22. S. S. Sekhon, B. S. Lalia, J.-S. Park, C.-S. Kim, and K. Yamada, J. Mater. Chem., 16, 2256 (2006)

23. S. S. Sekhon, P. Krishnan, B. Singh, K. Yamada, and C. S. Kim, Electrochim. Acta, 52, 1639 (2006)

24. M. A. B. H. Susan, A. Noda, S. Mitsushima, and M. Watanabe, Chem. Commun. (Cambridge, U. K.), 938 (2003).

25. E. van de Ven, A. Chairuna, G. Merle, S. P. Benito, Z. Borneman, and K. Nijmeijer, J. Power Sources, 222, 202 (2013).

26. S.-Y. Lee, T. Yasuda, and M. Watanabe, J. Power Sources, 195, 5909 (2010).

27. K. Wippermann, J. Wackerl, W. Lehnert, B. Huber, and C. Korte, Journal of The Electrochemical Society, 163, F25 (2016).

28. D. Bridgeman, J. Corral, A. Quach, X. Xian, and E. Forzani, Langmuir, 30, 10785 (2014).

29. Y. Chen, Y. Cao, and T. Mu, Chem. Eng. Technol., 37, 527 (2014).

30. M. Krannich, F. Heym, and A. Jess, J. Chem. Eng. Data, 61, 1162 (2016)

31. M. Krannich, F. Heym, and A. Jess, Chem. Eng. Technol., 39, 343 (2016).

32. A. Kudasheva, T. Kamiya, Y. Hirota, and A. Ito, J. Membr. Sci., 499, 379 (2016)

33. S. Cuadrado-Prado, M. Dominguez-Perez, E. Rilo, S. Garcia-Garabal, L. Segade, C. Franjo, and O. Cabeza, Fluid Phase Equilib., 278, 36 (2009).

34. Y. Cao, Y. Chen, X. Sun, Z. Zhang, and T. Mu, Phys. Chem. Chem. Phys., 14, 12252 (2012).

35. A. C. MacMillan, T. M. McIntire, J. A. Freites, D. J. Tobias, and S. A. Nizkorodov, J. Phys. Chem. B, 116, 11255 (2012).

36. A. Maiti, A. Kumar, and R. D. Rogers, Phys. Chem. Chem. Phys., 14, 5139 (2012).

37. J. Schenk, U. Panne, and M. Albrecht, J. Phys. Chem. B, 116, 14171 (2012)

38. Y. Chen, Y. Cao, X. Lu, C. Zhao, C. Yan, and T. Mu, New J. Chem., 37, 1959 (2013).

39. Y. Cao, X. Sun, Y. Chen, and T. Mu, ACS Sustainable Chem. Eng., 2, 138 (2014).

40. A. C. MacMillan, T. M. McIntire, S. A. Epstein, and S. A. Nizkorodov, J. Phys. Chem. C, 118, 29458 (2014).

41. N. C. Merkel, C. Roemich, R. Bernewitz, H. Kuenemund, M. Gleiss, S. Sauer, T. J. S. Schubert, G. Guthausen, and K. Schaber, J. Chem. Eng. Data, 59, 560 (2014).

42. D. A. Walsh, A. Ejigu, J. Smith, and P. Licence, Phys Chem Chem Phys, 15, 7548 (2013).

43. D. A. Walsh, A. Ejigu, S. Muhammad, and P. Licence, ChemElectroChem, 1, 281 (2014).

44. K. Motobayashi and M. Osawa, Electrochem. Commun. 65, 14 (2016).

45. G. Feng, X. Jiang, R. Qiao, and A. A. Kornyshev, ACS Nano, 8, 11685 (2014)

46. Y. Zhong, J. Yan, M. Li, L. Chen, and B. Mao, ChemElectroChem, 3, 2221 (2016)

47. J. Friedl, I. I. E. Markovits, M. Herpich, G. Feng, A. A. Kornyshev, and U. Stimming, ChemElectroChem, 4, 216 (2017).

48. K. Wippermann, J. Giffin, S. Kuhri, W. Lehnert, and C. Korte, Physical Chemistry Chemical Physics, 19, 24706 (2017).

49. SciFinder, value taken from substance search with substance identifier,107-68-6', predicted value calculated using Advanced Chemistry Development (ACD/Labs) Software V11.02 (2017)

50. SciFinder, value taken from substance search with substance identifier,616-39-7', predicted value calculated using Advanced Chemistry Development (ACD/Labs) Software V11.02 (2017).

51. W. Maier, Phosphorsäureverteilung in Membran-Elektroden-Einheiten dynamisch betriebener Hochtemperatur-Polymerelektrolyt-Brennstoffzellen, in, p. 79, Jülich (2013).

52. S. D. Nickerson, E. M. Nofen, H. Chen, M. Ngan, B. Shindel, H. Yu, and L. L. Dai, J. Phys. Chem. B, 119, 8764 (2015).

53. J. Vila, P. Ginés, E. Rilo, O. Cabeza, and L. M. Varela, Fluid Phase Equilibria, 247, 32 (2006).

54. Y. Furuya, T. Mashio, A. Ohma, M. Tian, F. Kaveh, D. Beauchemin, and G. Jerkiewicz, ACS Catalysis, 5, 2605 (2015).

55. A. Zolfaghari and G. Jerkiewicz, J. Electroanal. Chem., 420, 11 (1997)

56. A. Zolfaghari and G. Jerkiewicz, J. Electroanal. Chem., 422, 1 (1997)

57. A. Zolfaghari, M. Chayer, and G. Jerkiewicz, J. Electrochem. Soc., 144, 3034 (1997).

58. Y. Furuya, T. Mashio, A. Ohma, N. Dale, K. Oshihara, and G. Jerkiewicz, J. Chem. Phys., 141, 164705/1 (2014). 